EXTENDED REPORT

\title{
Thrombotic microangiopathic haemolytic anaemia and antiphospholipid antibodies
}

\author{
G Espinosa, S Bucciarelli, R Cervera, M Lozano, J-C Reverter, G de la Red, V Gil, M Ingelmo, \\ J Font, R A Asherson
}

Ann Rheum Dis 2004;63:730-736. doi: 10.1136/ard.2003.007245

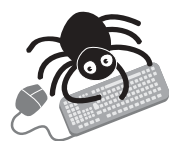

Tables $\mathrm{W} 1$ and $\mathrm{W} 2$ are available at http:// www.annrheumdis.com/ supplemental

See end of article for authors' affiliations

..........

Correspondence to: Dr R Cervera, Servei de Malalties Autoimmunes, Hospital Clínic, Villarroel 170, 08036, Barcelona, Catalonia, Spain

rcervera@clinic.ub.es

Accepted 14 June 2003
Objective: To analyse the clinical and laboratory features of patients with thrombotic microangiopathic haemolytic anaemia (TMHA) associated with antiphospholipid antibodies (aPL).

Methods: A computer assisted (PubMed) search of the literature was performed to identify all cases of TMHA associated with aPL from 1983 to December 2002.

Results: 46 patients (36 female) with a mean (SD) age at presentation of TMHA of 34 (15) years were reviewed. Twenty eight (61\%) patients had primary antiphospholipid syndrome (APS). TMHA was the first clinical manifestation of APS in 26 (57\%) patients. The clinical presentations were haemolytic-uraemic syndrome $(26 \%)$, catastrophic APS $(23 \%)$, acute renal failure $(15 \%)$, malignant hypertension (13\%), thrombotic thrombocytopenic purpura (13\%), and HELLP (haemolysis, elevated liver enzymes, and low platelet count in association with eclampsia) syndrome (4\%). Lupus anticoagulant was detected in $86 \%$ of the episodes of TMHA, and positive anticardiolipin antibodies titres in $89 \%$. Steroids were the most common treatment (69\% of episodes), followed by plasma exchange (PE) (62\%), anticoagulant or antithrombotic agents (48\%), immunosuppressive agents (29\%), and immunoglobulins (12\%). Recovery occurred in only 10/29 (34\%) episodes treated with steroids, and in 19/27 (70\%) episodes treated with PE. Death occurred in 10/46 (22\%) patients.

Conclusions: The results emphasise the need for systematic screening for aPL in all patients with clinical and laboratory features of TMHA. The existence of TMHA in association with an APS forces one to rule out the presence of the catastrophic variant of this syndrome. PE is indicated as a first line of treatment for all patients with TMHA associated with aPL.
$\mathrm{T}$ he term thrombotic microangiopathic haemolytic anaemia (TMHA) was introduced by Symmers in 1952 to describe clinical disorders related to the presence of localised or diffuse microvascular thrombosis. ${ }^{1}$ TMHA is characterised by thrombocytopenia, microangiopathic haemolytic anaemia (as indicated by erythrocyte fragmentation on peripheral blood smears) accompanied by a negative Coombs' test, fever, neurological symptoms, and kidney involvement. ${ }^{2}$ The conditions that should be considered in the differential diagnosis of TMHA include thrombotic thrombocytopenic purpura (TTP), haemolytic-uraemic syndrome (HUS), acute postpartum and contraceptive associated renal failure, malignant hypertension, HELLP (haemolysis, elevated liver enzymes, and low platelet count in association with eclampsia) syndrome, cancer, immunosuppressive treatment, systemic sclerosis, undifferentiated connective tissue disorder, and human immunodeficiency virus infection. $^{3}$ Typical histological findings in this syndrome include hyaline thrombi composed of fibrin and platelets which occlude the microvasculature.

Recently, several reports have pointed out the relationship of TMHA with the presence of antiphospholipid antibodies (aPL). ${ }^{4}$ Systemic lupus erythematosus (SLE) was the first autoimmune disease in which the association of TMHA with aPL was recognised..$^{6-8}$ In some patients with SLE it was found that renal lesions of TMHA might develop during the course of TTP or HUS or be associated with antiphospholipid syndrome (APS), regardless of the underlying type of lupus glomerulopathy existing. ${ }^{90}$ In the reports of coexistent SLE and TTP, lupus anticoagulant (LA) was documented in 2 of 12 patients $^{511}$ and anticardiolipin antibodies (aCL) were recorded in 4 of 5 patients examined..$^{512}$ Patients with a previously diagnosed APS may also develop TMHA. ${ }^{4}{ }^{13}{ }^{14}$ One of these reported cases was a patient with a 7 year history of SLE complicated by APS who later developed TTP. ${ }^{13}$ Therefore, an association between aPL and the development of TMHA is clearly evident.

In this article we analyse the clinical and laboratory features of 46 patients -45 taken from published reports and one from our clinics-with TMHA associated with aPL, and support the hypothesis that TMHA might be a manifestation of the APS.

\section{METHODS}

A computer assisted (PubMed, National Library of Medicine, Bethesda, MD) search of the literature was performed to identify all cases of TMHA associated with aPL published in English, Spanish, and French from 1983 (when APS was first defined) ${ }^{15}$ to December 2002 (keywords: microangiopathic haemolytic anaemia, thrombotic microangiopathy, microangiopathic anaemia, thrombotic thrombocytopenic purpura, haemolytic-uraemic syndrome, schistocytes, malignant hypertension, phospholipid, antiphospholipid, antiphospholipid syndrome, antiphospholipid antibodies, anticardiolipin, anticardiolipin antibodies, lupus anticoagulant, coagulation inhibitor, lupus inhibitor), and bibliographies of all articles

Abbreviations: aCL, anticardiolipin antibodies; aPL, antiphospholipid antibodies; APS, antiphospholipid syndrome; FFP, fresh frozen plasma; HELLP, haemolysis, elevated liver enzymes, and low platelet count in association with eclampsia; HUS, haemolytic-uraemic syndrome; LA, lupus anticoagulant; PE, plasma exchange; SLE, systemic lupus erythematosus; TMHA, thrombotic microangiopathic haemolytic anaemia; TTP, thrombotic thrombocytopenic purpura; vWF, von Willebrand factor 
were scanned for references not identified in the initial search. Only cases with well documented clinical summaries and relevant information were included. Data were summarised using a standardised data form, including sex, age, previous abortions or thrombotic events, immunological features, treatment, and evolution (web extra table Wl, available at http://www.annrheumdis.com/supplemental).

For practical purposes, patients were included only if they had the following criteria: microangiopathic haemolytic anaemia, as indicated by erythrocyte fragmentation (schistocytes) on peripheral blood smears, with a negative Coombs' test, thrombocytopenia, and presence of LA or positivity for aCL, or both. We categorised patients as having TTP if neurological dysfunction predominated, whereas patients with predominantly glomerular damage were diagnosed as the HUS.

To facilitate synthesis of these data we categorised patients in the following diagnostic categories:

- SLE, if they met four or more criteria of the American College of Rheumatology revised criteria for the classification of SLE ${ }^{1617}$

- "Lupus-like" syndrome if they met only two or three criteria

- "Primary" APS if they met criteria of the international consensus statement on preliminary classification criteria for definite APS syndrome, ${ }^{18}$ and did not meet any of the above described criteria for SLE or lupus-like syndrome

- "Catastrophic" APS if they presented with an acute devastating APS with multiple organ involvement, as previously defined. ${ }^{19}$

\section{RESULTS}

A total of 63 patients with TMHA associated with aPL were found in the literature search, but 18 of them (corresponding to six articles) $)^{20-25}$ were not included because their clinical and immunological characteristics were not described. Because of this, 46 patients-45 from the literature ${ }^{4}{ }_{13} 1426-51$ and one from our clinics (see appendix 1)—with 47 episodes of TMHA (one patient had two episodes of $\mathrm{TMHA}^{40}$ ) were finally reviewed.

\section{General characteristics}

Table 1 shows the general clinical features of the complete series of patients. The patients comprised 36 (78\%) women and $10(22 \%)$ men with a mean (SD) age of $34(15)$ years (range 7-73). Twenty eight (61\%) patients had primary APS, $15(33 \%)$ patients were categorised as having APS associated with defined SLE, $2(4 \%)$ with lupus-like syndrome, and 1 $(2 \%)$ with systemic sclerosis of paraneoplastic origin. During the follow up, the first diagnosis of primary APS was changed in three patients: one patient ${ }^{32}$ developed a clinical picture of SLE 3 months later, another patient ${ }^{14}$ developed a lupus-like syndrome 9 months later, and another ${ }^{46}$ developed SLE 4 years later. In addition, one patient ${ }^{35}$ had multicentric Castleman's disease, and the necropsy of another patient disclosed a carcinoma of the uterus with pleural, bone, and hepatic metastasis. ${ }^{41}$

\section{Clinical presentation and precipitating factors}

In $26(57 \%)$ patients, TMHA was the first clinical manifestation of APS, whereas a total of seven (15\%) patients had a previous history of major vascular occlusions. Deep venous thrombosis was reported as occurring in four $(9 \%)$ patients, and in one this was accompanied by pulmonary embolism. Arterial occlusions occurred in two (4\%) patients, arteriovenous fistula thrombosis in one, and haemodialysis vascular access and renal graft thrombosis in one patient.
Table 1 General characteristics of 46 patients (mean age 34 years)with thrombotic microangiopathic haemolytic anaemia associated with antiphospholipid antibodies

\begin{tabular}{lc}
\hline Characteristic & No (\%) \\
\hline Sex & $36(78)$ \\
$\quad$ Female & $10(22)$ \\
$\quad$ Male & \\
Autoimmune diseases & $28(61)$ \\
Primary APS & $15(33)$ \\
SLE & $2(4)$ \\
Lupus-like & $1(2)$ \\
Systemic sclerosis of paraneoplastic origin & \\
\hline
\end{tabular}

Spontaneous abortions or fetal death had occurred in 14 (39\%) of the 36 female patients.

Table 2 shows the clinical presentation of 47 episodes of TMHA. HUS was the most common clinical presentation $(26 \%)$, occurring in the postpartum period in three patients, and then catastrophic APS (23\%), acute renal failure (15\%), malignant hypertension (13\%), TTP (13\%), HELLP syndrome $(4 \%)$, amaurosis fugax with microangiopathic haemolytic anaemia $(2 \%)$, thrombocytopenia $(2 \%)$, and thrombotic microangiopathy in renal allograft $(2 \%)$.

In $21 / 46(46 \%)$ patients, some precipitating factors contributed to the development of TMHA (table 3). This occurred during pregnancy in nine patients (fetal death in one patient) and in the postpartum period in six patients (one with acute enterocolitis). Major surgical procedures were evident as precipitating factors in three patients (one vascular surgery and two after renal transplantation), infection in two, and renal biopsy and oral contraceptive use (one case each).

\section{Histopathological studies}

Histopathological studies were performed in 32 patients (kidney biopsy in 27). The major finding was the presence of fibrin thrombi in glomerular capillaries in 18/24 (75\%) patients, followed by double contours in glomerular capillary walls in $12 / 24(50 \%)$, ischaemic glomeruli in $11 / 24(46 \%)$, fibrin thrombi in arterioles in 11/24 (46\%), and interlobular arteries in $8 / 24(33 \%)$. In three cases the results of renal histopathological examination were reported only as "consistent with thrombotic microangiopathy". In all cases, histological examination ruled out the presence of vasculitis.

Table 2 Clinical presentation of 47 episodes of thrombotic microangiopathic haemolytic anaemia associated with antiphospholipid antibodies

\begin{tabular}{ll}
\hline Clinical presentation & No (\%) \\
\hline Haemolytic uraemic syndrome & $12(26)$ \\
Catastrophic antiphospholipid syndrome & $11(23)$ \\
Acute renal failure & $7(15)$ \\
In postpartum period & 3 \\
Pregnancy related & 3 \\
Malignant hypertension & $6(13)$ \\
Thrombotic thrombocytopenic purpura & $6(13)$ \\
HELLP syndrome & $2(4)$ \\
Amaurosis fugax with microangiopathic haemolytic & $1(2)$ \\
anaemia & $1(2)$ \\
Thrombocytopenia & $1(2)$ \\
Thrombotic microangiopathy in renal allograft & \\
\hline
\end{tabular}




\begin{tabular}{|c|c|}
\hline Precipitating factors & No (\%) \\
\hline Obstetric complications & $15(33)$ \\
\hline During pregnancy & 9 \\
\hline In the postpartum period & 6 \\
\hline Major surgical and invasive procedures & $4(9)$ \\
\hline After renal transplantation & 2 \\
\hline Vascular surgery & 1 \\
\hline Renal biopsy & 1 \\
\hline Infections & $2(4)$ \\
\hline Oral contraceptives & 1 (2) \\
\hline
\end{tabular}

\section{Laboratory findings}

Table 4 shows the laboratory pattern of the patients in this series. LA was detected in 31/36 (86\%) episodes of TMHA in which this test was performed. The aCL titre was positive in $39 / 44(89 \%)$ episodes of TMHA. This comprised all patients who tested positive for the IgG isotype of aCL, $50 \%$ of patients who were positive for the IgM isotype, and only one patient who was positive for the $\operatorname{IgA}$ isotype. Both LA and aCL positivity were detected in 22/33 (67\%) patients. Antinuclear antibodies were positive in 15/29 (52\%) patients. Anti-dsDNA antibodies were found in 7/24 (29\%) patients, all of them with defined SLE.

\section{Treatment and outcome}

Table 5 shows the treatment of the 47 episodes of TMHA. For the statistical analysis, each episode of TMHA was considered separately, including those in the patients who had recurrences. Data on treatment were not available in five patients. Finally, 42 episodes of TMHA were analysed. Steroids (usually in high doses) were the most common treatment, used in 29/42 (69\%) episodes. Plasma exchange (PE) was used in the treatment of $62 \%$ of episodes. Fresh frozen plasma (FFP) was given as replacement fluid in $13(50 \%)$ episodes, together with normal saline in two, and with albumin in one; $5 \%$ albumin in two (8\%) episodes; and in 12 episodes this information was not specifically reported. In four ( $10 \%$ ) episodes, infusion of FFP without plasma removal was used as treatment. Twenty (48\%) episodes of TMHA were treated with some form of anticoagulant or antithrombotic agent (heparin in nine, aspirin in eight, dipyridamole in four, and oral anticoagulant in three). Immunosuppressive agents were used in $12(29 \%)$ cases (cyclophosphamide in 10 , vincristine in two, and azathioprine in one). Intravenous immunoglobulins were used in five $(12 \%)$. Intravenous prostaglandin El was used in one case. Most patients, however, received a combination of these treatments (web extra table W2, available at http://www.annrheumdis.com/ supplemental).

\begin{tabular}{|c|c|}
\hline Immunological features & No/total number (\%) \\
\hline Lupus anticoagulant & $31 / 36(86)$ \\
\hline $\mathrm{aCl}$ & $39 / 44(89)$ \\
\hline $\lg G$ aCl & $27 / 27(100)$ \\
\hline $\lg M a C L$ & $11 / 22(50)$ \\
\hline ANA & $15 / 29(52)$ \\
\hline Anti-dsDNA & $7 / 24(29)$ \\
\hline
\end{tabular}

aCL, anticardiolipin antibodies; ANA, antinuclear antibodies; antidsDNA, anti-double stranded DNA antibodies.
Table 5 Treatment of 42 episodes of thrombotic microangiopathic haemolytic anaemia associated with antiphospholipid antibodies

\begin{tabular}{lc}
\hline Treatment & No (\%) \\
\hline Steroids & $29(69)$ \\
Plasma exchange & $26(62)$ \\
FFP as replacement fluid & 13 \\
FFP with normal saline & 2 \\
FFP with albumin & 1 \\
Albumin & 2 \\
Infusion of FFP without plasma removal & $4(10)$ \\
Anticoagulant or antithrombotic agent & $20(48)$ \\
Heparin & 9 \\
Aspirin & 8 \\
Dipyridamole & 4 \\
Oral anticoagulant & 3 \\
Immunosuppressive agents & $12(29)$ \\
Cyclophosphamide & 10 \\
Vincristine & 2 \\
Azathioprine & 1 \\
Intravenous immunoglobulins & $5(12)$ \\
\hline FFP, fresh frozen plasma. &
\end{tabular}

When the presence or not of a single treatment is considered, recovery occurred in only 10/29 (34\%) episodes treated with steroids (in all of them, steroids were used together with other treatments). In the seven cases in which steroids were the unique first treatment used, the clinical status and laboratory abnormalities worsened. Recovery occurred in 19 of the $26(73 \%)$ episodes treated with PE. In nine patients this treatment was not the first treatment used, and its use correlated with a marked improvement of the laboratory abnormalities and patients' clinical status. Specifically, one patient presenting with a clinical picture of TTP was initially treated with steroids. ${ }^{31}$ No change in her neurological status was seen and the platelet count decreased. PE was then used, and the patient's neurological status improved and the platelet count rose. The same clinical course was seen in four additional patients, ${ }^{32} 4451$ initially treated with steroids, heparin, and infusions of FFP and intravenous immunoglobulins. Indeed, one patient, presenting with malignant hypertension who had improved with PE, had a recurrence of thrombocytopenia upon withdrawal of PE. ${ }^{14}$ Another patient developed thrombocytopenia and worsening of her neurological status 3 weeks after the acute episode of catastrophic APS supervened. ${ }^{48}$ Intravenous immunoglobulin was added but her mental status continued to deteriorate. Monthly intravenous cyclophosphamide did not improve the clinical status and, finally, PE was restarted. Significant improvement was noted within 48 hours, and the patient responded to repeated PE over 3 years. Only in one case was heparin use directly related to an improvement in laboratory abnormalities and clinical status. ${ }^{13}$ In four cases this improvement appeared when heparin was used together with other treatments (in three of them PE). In the remaining four cases in which heparin use was not followed by a clinical improvement, PE was not used. Considering the four patients treated with infusions of FFP, in two of them no significant response was noted and the remaining two were discharged, but renal function remained impaired.

Of seven patients who presented with vascular occlusions before the development of an acute episode of TMHA, only three were receiving anticoagulant treatment (two of them, prolonged oral anticoagulant treatment, and the third patient, aspirin and heparin subcutaneously during pregnancy and recurrent spontaneous abortions).

Among the 46 patients, 10 (22\%) finally died. Specifically, death occurred in three patients with clinical presentation of catastrophic APS, two with TTP, two with HUS, and 
thrombocytopenia, malignant hypertension, and acute renal failure (one case each). The causes of death were catastrophic APS (three patients), infection (three patients), and myocardial infarction, massive cerebral haemorrhage, and massive haemorrhage after abdominal surgery (one case each). The remaining patient ${ }^{37}$ illustrates the difficulty of establishing the differential diagnosis between TTP and catastrophic APS. This patient presented with a clinical picture of SLE with diffuse proliferative glomerulonephritis and thrombotic microangiopathy. In the post-biopsy course, she developed shortness of breath with bilateral pleural effusions. Renal function continued to deteriorate and then generalised tonicclonic seizure occurred. At this moment, thrombocytopenia and haemolytic anaemia with an increase in schistocytes was noted, and an LA was detected. Finally, arterial desaturation occurred with a synus bradycardia, which progressed to asystole and was followed by unsuccessful resuscitation. The postmortem examination of this patient showed extensive arteriolar and small arterial hyaline thrombi in multiple organs, including the myocardium, cerebral cortex, pancreas, kidney, and genitourinary tract. In some cases, the differential diagnosis between TTP and catastrophic APS remains difficult, and the patient described is an example of this problem (Appendix 1).

\section{DISCUSSION}

The term TMHA was first introduced to describe conditions in which localised or diffuse microvascular thrombosis occurs. ${ }^{1}$ TMHA encompasses a spectrum of disorders including TTP, HUS, malignant hypertension, postpartum renal failure, preeclampsia, and scleroderma renal crisis. The typical clinical picture may be complicated by thrombocytopenia, microangiopathic haemolytic anaemia, fever, neurological symptoms, and/or renal dysfunction, but not all these manifestations are required. Table 6 shows an attempt to establish a differential diagnosis of disorders that present with TMHA.

An intriguing question is whether aPL may have a role in the development of TMHA in patients with SLE. On the one hand, because aPL are present in up to $50 \%$ of patients with $\mathrm{SLE}^{52}$ a positive aPL assay could be expected in a similar proportion of patients with SLE who develop TTP without necessarily implying an existing causal relationship. In a review of 28 patients with SLE and TMHA performed by Nesher et al, ${ }^{53}$ tests for LA or aCL were reported in eight patients and were positive in five. The contribution of aPL to the association of TTP and SLE was also suggested by the review of Musio et al. ${ }^{44}$ These authors detected aCL in nearly half of the patients tested (8/17) and the LA was seen in $14 \%$ $(2 / 14)$.

The role of aPL in idiopathic TMHA is controversial. Although aPL have not commonly been detected in primary $\mathrm{TTP}^{54}{ }^{55}$ or HUS, ${ }^{20}$ there are some data favouring a causal relationship. Ardiles et al studied 17 patients presenting with diarrhoea associated HUS. ${ }^{20}$ The possibility of SLE was excluded clinically and by laboratory tests. IgG aCL were present in eight patients, two patients had IgM aCL, and one had IgA antibodies on the solid phase enzyme linked immunosorbent aCL assays. Von Tempelhoff et al studied the incidence of acquired and/or inherited thrombophilia in 32 women with HELLP syndrome. ${ }^{56}$ Twenty two of them presented with aPL positivity: 17 with LA and 15 with aCL. They concluded that the aPL were the predominant thrombophilia defect, being present in $69 \%$ of patients with HELLP syndrome and thrombophilia defects. Most cases of HELLP syndrome are however aPL negative. Indeed, in our review, $28(61 \%)$ patients were categorised as having a primary APS, and TMHA was the first manifestation of the APS in 26 (93\%) of them. In the light of these data, we may conclude that in some patients (with or without SLE), aPL may play a part in the development of TMHA.

The aetiology of TMHA, especially in autoimmune diseases, is unclear. Systemic endothelial cell damage appears to be a central phenomenon in the pathogenesis of all TMHA syndromes. Direct evidence for this is the demonstration of apoptosis of microvascular endothelial cells in spleens removed from patients with $\mathrm{TTP}^{57}$ and the demonstration that plasma from patients with TTP or adult HUS can cause apoptosis of microvascular endothelial cells. ${ }^{58}$ Endothelial damage, regardless of its aetiology, may result in widespread release of unusually large von Willebrand factor (vWF) multimers. A plasma vWF-cleaving protease (a metalloproteinase) has been postulated to decrease the size of large vWF multimers to their normal size in plasma after secretion. Deficiency of this protease has been reported in patients with acute idiopathic TTP, ${ }^{59}$ and an IgG autoantibody to the enzyme itself is responsible for its depletion. vWF-cleaving protease deficiency may result in larger plasma vWF multimers that can cause platelet agglutination. ${ }^{60}$ However, these abnormalities may not be specific for idiopathic TTP. Other studies have shown that thrombotic episodes, especially arterial thrombosis, were more common in LA positive patients with low vWF-cleaving protease activity. ${ }^{61}$ Moreover, Diez-Ewald et al found that vWF was significantly higher in patients with LA and thromboses and considered that the increased vWF was derived from endothelial cells damaged by LA. ${ }^{62}$ An abnormal vWF multimeric pattern was found in $71 \%$ of patients with multiple abortions and in $50 \%$ of those with strokes. ${ }^{63}$ These results suggest that decreased activity of vWF-cleaving protease may be an additional risk factor for arterial thrombosis in patients with aPL. Trent et al described two patients with chronic relapsing TTP and aPL. ${ }^{25}$ The first was found to have unusually large vWF multimers in her plasma during TTP remission. Plasma of the second patient has not been analysed for the presence of unusually large vWF multimers. We could not include these two patients in our review because the aPL encountered were antiphosphatidylinositol $\operatorname{IgM}$ and antiphosphatidylserine IgM respectively, with aCL and LA negativity. Mukai et al described a patient with arterial thromboses in APS

Table 6 Differential diagnosis of thrombotic microangiopathic haemolytic anaemia

\begin{tabular}{|c|c|c|c|c|}
\hline & HUS & Catastrophic APS & TाP & $\begin{array}{l}\text { Malignant } \\
\text { hypertension }\end{array}$ \\
\hline Thrombocytopenia & + & ++ & +++ & + \\
\hline $\begin{array}{l}\text { Microangiopathic haemolytic } \\
\text { anaemia }\end{array}$ & + & + & + & + \\
\hline Fever & + & $+1-$ & ++ & - \\
\hline CNS disease & + & ++ & ++ & + \\
\hline Renal disease & ++ & + & + & ++ \\
\hline Hypertension & + & $+1-$ & $+/-$ & +++ \\
\hline
\end{tabular}

HUS, haemolytic-uraemic syndrome; APS, antiphospholipid syndrome; TTP, thrombotic thrombocytopenic purpura; CNS, central nervous system. 
associated with an excess of a large multimer of vWF. ${ }^{64}$ Unfortunately, these authors did not measure the activity of vWF-cleaving protease or the antibodies. Until now, the levels of vWF-cleaving protease have only been investigated in one patient with SLE and aPL who developed TTP or a TTPlike syndrome, similar to catastrophic APS. ${ }^{65}$ The authors found a decreased vWF-cleaving protease activity. On the basis of this finding, it is possible that some cases of catastrophic APS had been diagnosed as TTP and/or cases of TTP had been diagnosed as catastrophic APS. As there are no more reports of any relationship between this protease, phospholipids, and TMHA, further evaluation is needed.

As we indicated above, endothelial damage is thought to be another important aetiological factor in some forms of TMHA, resulting in the release of unusually large vWF forms, theoretically overwhelming physiological degradation systems and causing a relative deficiency of vWF-cleaving protease. ${ }^{66}$ Patients with malignant hypertension or HELLP syndrome (17\% of the patients in our review) showed endothelial injury, indicated by the higher vWF levels and raised serum levels of vascular cell adhesion molecule- 1 and E-selectin, respectively. ${ }^{67}{ }^{68}$ There is evidence that endothelial cells do appear to have a role in the induction of the prothrombotic diathesis of the APS. Autoantibodies including aPL, anti-endothelial cell, and anti-dsDNA have all been shown to react with endothelial cells, providing a stimulatory signal, and up regulation of adhesion molecules or tissue factor. Nakamura et al demonstrated that LA could induce apoptosis in umbilical vein endothelial cells, ${ }^{69}$ and the IgG from patients with aPL can enhance endothelial cell adhesion molecule expression and monocyte adherence. ${ }^{70}$

However, other pathogenic mechanisms cannot be completely ruled out ${ }^{71}$ because a decrease in specific vWFcleaving protease activity has been found in $89 \%$ of TTP patients but only in $13 \%$ of patients with HUS. ${ }^{72}{ }^{73}$ In addition, Hashimoto et al were able to find from lupus prone mice a hybridoma clone producing an antibody able to induce thrombotic microangiopathy with some characteristics of TTP when injected into syngeneic mice. ${ }^{74}$

The clinical picture of TMHA, SLE, and APS may overlap and, if any two of the three conditions coexist in the same patient, the diagnosis may be difficult at the time of initial presentation. In one patient the diagnosis of TTP was based on thrombocytopenia, microangiopathic haemolytic anaemia, motor epileptic fits, and fever without any evidence of infection or disseminated intravascular coagulation. The partial thromboplastin time was prolonged owing to the presence of LA. The authors excluded the diagnosis of catastrophic APS owing to the presence of microangiopathic haemolytic anaemia in the absence of any evidence of disseminated intravascular coagulation, but we consider that this patient might be categorised as having catastrophic APS. In some patients, the diagnosis of TTP does not exclude the diagnosis of catastrophic APS, but TTP specifically and TMHA, in general, may be the clinical presentation of an APS.

Patients treated with PE had a recovery rate of $73 \%$. In fact, $\mathrm{PE}$ is the most important component of treatment and is indicated for all patients with suspected TTP and HUS. ${ }^{75}$ However, in contrast with TTP, where the infusion of healthy plasma, in addition to the removal of the patient's plasma, is very important for recovery, some published reports (exemplified in the patient reported here) suggest that in the case of catastrophic APS, removal of the plasma containing the damaging substance may be enough to establish remission without the need for the infusion of healthy plasma. Because plasma infusion is generally associated with more severe immediate adverse effects than infusion of $5 \%$ albumin, ${ }^{76}$ and because FFP may on occasion be associated with severe complications $^{77}$ whereas albumin solution is almost free of side effects, it might be advisable to begin treatment of a catastrophic APS with PE using 5\% albumin as a replacement fluid and, only when there is a lack of prompt response, consider the use of FFP. The value of additional treatments (especially antiplatelet drugs and steroids) is unknown. An appropriate randomised study to assess the role of steroids has not been carried out. Consequent on this analysis and review, we recommend, in cases of TMHA in association with APS, the use of PE as a first line of treatment. However, steroids should be still used in association with anticoagulation, in order to limit or treat the massive cytokine release.

In conclusion, TMHA is a rare complication in patients with APS but it may be the first clinical manifestation of this syndrome. Furthermore, it may be part of the multiorgan failure syndrome seen in patients with catastrophic APS. This would support the need for systematic screening for LA and aCL in all patients with clinical and laboratory features of microangiopathic haemolytic anaemia. In addition, the existence of TMHA in an APS mandates the ruling out of the existence of the catastrophic variant of this syndrome. $\mathrm{PE}$, perhaps using albumin as the initial replacement fluid, is the most important component of treatment and is indicated as first line of treatment for all patients with TMHA associated with aPL.

\section{ACKNOWLEDGEMENTS}

Supported by Spanish Grants FIS 99/0280, 99/0148, and 00/1048. Gloria de la Red is a research fellow sponsored by a grant from Hospital Clinic, Barcelona, Spain.

\section{Authors' affiliations}

G Espinosa, S Bucciarelli, R Cervera, G de la Red, V Gil, M Ingelmo, J Font, Department of Autoimmune Diseases, Institut Clínic d'Infeccions i Immunologia, Institut d'Investigacions Biomèdiques August Pi i Sunyer, Barcelona, Catalonia, Spain

M Lozano, J-C Reverter, Department of Haemotherapy and Haemostasis, Hospital Clínic, Institut d'Investigacions Biomèdiques August $\mathrm{Pi}$ i Sunyer, Barcelona, Catalonia, Spain

R A Asherson, Rheumatic Diseases Unit, Department of Medicine, University of Cape Town School of Medicine, Cape Town, South Africa

\section{APPENDIX 1}

\section{CASE REPORT}

A 32 year old man was admitted with a 2 week history of confusion, headache, vomiting, abdominal pain, and fatigue. His previous medical and surgical history was unremarkable, and no drugs had been taken previously. On admission, the patient appeared confused with a bi-temporal headache. Blood pressure was 155/90 mm Hg and physical examination did not disclose any significant findings, except for a distended, non-tender abdomen. Bowel sounds were sluggish. Initial laboratory data included white blood cell count $9.6 \times 10^{9} / 1$ with normal differential, haemoglobin $86 \mathrm{~g} / \mathrm{l}$, platelet count $48 \times 10^{9} / \mathrm{l}$, lactate dehydrogenase $1159 \mathrm{IU} / \mathrm{l}$ (normal range 250-450), haptoglobin $0.087 \mathrm{~g} / \mathrm{l} \quad(0.320$ $1.810)$, and serum creatinine $140 \mu \mathrm{mol} / \mathrm{l}(30-110)$. Both direct and indirect Coombs' test were negative and peripheral blood smear showed many schistocytes. Urine analysis showed $2+$ protein with mild haematuria (10 red blood cells/high power field). The prothrombin time and activated partial thromboplastin time were within the normal ranges, and normal D-dimer levels were found. Magnetic resonance imaging of the brain showed changes consistent with mild microvascular ischaemia in the cerebral white matter.

Soon after his admission, he developed episodes of an acute coronary syndrome (angina), and an electrocardiogram showed $\mathrm{T}$ wave inversion and $\mathrm{Q}$ waves on the inferior surface. 
Creatine kinase and troponine $\mathrm{T}$ tests were normal. A myocardial gammagraphy perfusion study showed mild anterolateral and inferior ischaemia. LA (determined following the guidelines of the Subcommittee for the Standardisation of Lupus Anticoagulants of the International Society of Thrombosis and Hemostasis ${ }^{78}$ ) was present and aCL IgG, measured using standardised enzyme linked immunosorbent assay (ELISA; Chesire Diagnostics, Chester, United Kingdom), was markedly raised at 65.9 IgG phospholipid (GPL) units (normal<15 GPL units). Antinuclear, anti-double stranded DNA antibodies, rheumatoid factor, and cryoglobulin levels were negative. Because of altered mental status, microangiopathic haemolytic anaemia, thrombocytopenia, renal failure, and cardiac involvement, a presumptive diagnosis of catastrophic APS was made.

Treatment was started with PE using 5\% albumin as replacement fluid (four sessions), intravenous prednisolone ( $80 \mathrm{mg}$ daily), and intravenous heparin. After 20 days in hospital, his neurological, renal, and cardiac status stabilised and thrombocytopenia and microangiopathic haemolytic anaemia resolved. During 12 months of follow up, with tapering doses of prednisone and coumadin adjusted to an international normalised ratio of 2.5-3.5, there was no evidence of recurrent thromboembolism, although aCL IgM titres remained high (68 MPL units) and LA was still present.

\section{REFERENCES}

1 Symmers W. Thrombotic microangiopathic haemolytic anaemia (thrombotic microangiopathy). BMJ 1952;ii:897-903.

2 Ruggenenti P, Remuzzi G. Thrombotic thrombocytopenic purpura and related disorders. Hematol Oncol Clin North Am 1990;4:219-41.

3 Scully RE, Mark EJ, McNeely WF, Ebeling SH, Phillips LD. Case records of the Massachusetts General Hospital. Weekly clinicopathological exercises. Case 20-1997. N Engl J Med 1997;336:1895-903.

4 Durand JM, Lefevre P, Kaplanski G, Soubeyrand J. Thrombotic microangiopathy and the antiphospholipid antibody syndrome. J Rheumatol 1991;18:1916-18.

5 Hess DC, Sethi K, Awad E. Thrombotic thrombocytopenic purpura in systemic lupus erythematosus and antiphospholipid antibodies: effective treatment with plasma exchange and immunosuppression. J Rheumatol 1992;19:1474-8.

6 Glueck HI, Kant KS, Weiss MA, Pollak VE, Miller MA, Coots M. Thrombosis in systemic lupus erythematosus. Relation to the presence of circulating anticoagulants. Arch Intern Med 1985;145:1389-95.

7 Kant KS, Pollak VE, Weiss MA, Glueck HI, Miller AN, Hess EV. Glomerular thrombosis in systemic lupus erythematosus: prevalence and significance. Medicine (Baltimore) 1981;60:71-86.

8 Love PE, Santoro SA. Antiphospholipid antibodies: anticardiolipin and the lupus anticoagulant in systemic lupus erythematosus (SLE) and in non-SLE disorders. Prevalence and clinical significance. Ann Intern Med 1990; 112:682-98.

9 Farrugia E, Torres VE, Gastineau D, Michet CJ, Holley KE. Lupus anticoagulant in systemic lupus erythematosus: a clinical and renal pathological study. Am J Kidney Dis 1992;20:463-71.

10 Frampton G, Hicks J, Cameron JS. Significance of anti-phospholipid antibodies in patients with lupus nephritis. Kidney Int 1991;39:1225-31.

11 Gatenby PA, Smith H, Kirwan P, Lauer CS. Systemic lupus erythematosus and thrombotic thrombocytopenic purpura. A case report and review of relationship. J Rheumatol 1981;8:504-8.

12 Itoh Y, Sekine H, Hosono O, Takeuchi T, Koide J, Takano M, et al. Thrombotic thrombocytopenic purpura in two patients with systemic lupus erythematosus: clinical significance of anti-platelet antibodies. Clin Immunol Immunopathol 1990;57:125-36

13 Hughson MD, Nadasdy T, McCarty GA, Sholer C, Min KW, Silva F. Renal thrombotic microangiopathy in patients with systemic lupus erythematosus and the antiphospholipid syndrome. Am J Kidney Dis 1992;20:150-8.

14 Sirvent AE, Enriquez R, Antolin A, Cabezuelo JB, Gonzalez C, Arenas MD. Malignant hypertension and antiphospholipid syndrome. Nephron 1996;73:368-9

15 Harris EN, Baguley E, Asherson RA, Hughes GRV. Clinical and serological features of the antiphospholipid syndrome (APS). Br J Rheumatol 1987:26:19.

16 Tan EM, Cohen AS, Fries JF, Masi AT, McShane DJ, Rothfield NF, et al. The 1982 revised criteria for the classification of systemic lupus erythematosus. Arthritis Rheum 1982;25:1271-7.

17 Hochberg MC. Updating the American College of Rheumatology revised criteria for the classification of systemic lupus erythematosus. Arthritis Rheum 1997;40:1725

18 Wilson WA, Gharavi AE, Koike T, Lockshin MD, Branch DW, Piette JC, et al International consensus statement on preliminary classification criteria for definite antiphospholipid syndrome: report of an international workshop. Arthritis Rheum 1999;42:1309-11.

19 Asherson RA. The catastrophic antiphospholipid syndrome. J Rheumatol 1992;19:508-12.
20 Ardiles LG, Olavarria F, Elgueta M, Moya P, Mezzano S. Anticardiolipin antibodies in classic pediatric hemolytic-uremic syndrome: a possible pathogenic role. Nephron 1998;78:278-83.

21 Becquemont $L$, Thervet E, Rondeau E, Lacave R, Mougenot B, Sraer JD. Systemic and renal fibrinolytic activity in a patient with anticardiolipin syndrome and renal thrombotic microangiopathy. Am J Nephrol 1990; 10:254-8

22 Cacoub P, Wechsler B, Piette JC, Beaufils H, Herreman G, Bletry O, et al Malignant hypertension in antiphospholipid syndrome without overt lupus nephritis. Clin Exp Rheumatol 1993;11:479-85.

23 Descombes E, Droz D, Drouet L, Grunfeld JP, Lesavre P. Renal vascular lesions in lupus nephritis. Medicine (Baltimore) 1997;76:355-68.

24 Morita H, Suwa T, Daidoh H, Takeda N, Ishizuka T, Yasuda K. Case report: diabetic microangiopathic hemolytic anemia and thrombocytopenia with antiphospholipid syndrome. Am J Med Sci 1996;311:148-51.

25 Trent K, Neustater BR, Lottenberg R. Chronic relapsing thrombotic thrombocytopenic purpura and antiphospholipid antibodies: a report of two cases. Am J Hematol 1997:54:155-9.

26 Asherson RA, Cervera R, Piette JC, Shoenfeld Y, Espinosa G, Petri MA, et al Catastrophic antiphospholipid syndrome: clues to the pathogenesis from a series of 80 patients. Medicine (Baltimore) 2001;80:355-77.

27 Baid S, Pascual M, Williams Jr WW, Tolkoff-Rubin N, Johnson SM, Collins B, et al. Renal thrombotic microangiopathy associated with anticardiolipin antibodies in hepatitis C-positive renal allograft recipients. J Am Soc Nephrol 1999;10:146-53.

28 Bendon RW, Wilson J, Getahun B, Bel-Kahn J. A maternal death due to thrombotic disease associated with anticardiolipin antibody. Arch Pathol Lab Med 1987;111:370-2.

29 Cerveny KC, Sawitzke AD. Relapsing catastrophic antiphospholipid antibody syndrome: a mimic for thrombotic thrombocytopenic purpura? Lupus 1999:8:477-81.

30 Chew CG, Bannister KM, Mathew TH, Russ G, Seymour A. Thrombotic microangiopathy related to anticardiolipin antibody in a renal allograft. Nephrol Dial Transplant 1999;14:436-8.

31 do Sameiro Faria M, Mota C, Barbot J, Alvares S, Jardim H, Vilarinho A, et al. Haemolytic uraemic syndrome, cardiomyopathy, cutaneous vasculopathy and anti-phospholipid activity. Nephrol Dial Transplant 2000;15:1891-2.

32 Gherman RB, Tramont J, Connito DJ. Postpartum hemolytic-uremic syndrome associated with lupus anticoagulant. A case report. J Reprod Med 1999:44:471-4.

33 Grinberg AR, Heller PG, Correa G, Sarano JF, Molinas FC, Nicastro MA, et al. Sindrome antifosfolipídico catastrófico. Comunicación de dos formas de presentación. Medicina (Buenos Aires) 1999:59:743-6.

34 Huang JJ, Chen MW, Sung JM, Lan RR, Wang MC, Chen FF. Postpartum haemolytic uraemic syndrome associated with antiphospholipid activity. Nephrol Dyal Transplant 1998;13:182-6.

35 Jain R, Chartash E, Susin M, Furie R. Systemic lupus erythematosus complicated by thrombotic microangiopathy. Semin Arthritis Rheum 1994;24:173-82.

36 Kincaid-Smith P, Fairley KF, Kloss M. Lupus anticoagulant associated with renal thrombotic microangiopathy and pregnancy-related renal failure. Q J Med 1988:68:795-815.

37 Kniaz D, Eisenberg GM, Elrad H, Johnson CA, Valaitis J, Bregman H. Postpartum hemolytic uremic syndrome associated with antiphospholipid antibodies. A case report and review of the literature. Am J Nephrol 1992;12:126-33.

38 Kon SP, Kwan JT, Raftery MJ. Reversible renal failure due to the antiphospholipid antibody syndrome, pre-eclampsia and renal thrombotic microangiopathy. Clin Nephrol 1995;44:271-3.

39 Kupferminc MJ, Lee MJ, Green D, Peaceman AM. Severe postpartum pulmonary, cardiac, and renal syndrome associated with antiphospholipid antibodies. Obstet Gynecol 1994;83:806-7.

40 Lacueva J, Enriquez R, Cabezuelo JB, Arenas MD, Teruel A, Gonzalez C. Acute renal failure as first clinical manifestation of the primary antiphospholipid syndrome. Nephron 1993:64:479-80.

41 Lajoie G, Kumar S, Min KW, Silva FG. Renal thrombotic microangiopathy associated with multicentric Castleman's disease. Report of two cases. Am J Surg Pathol 1995;19:1021-8

42 Meyrier A, Becquemont L, Weill B, Callard P, Rainfray M. Hemolytic-uremic syndrome with anticardiolipin antibodies revealing paraneoplastic systemic scleroderma. Nephron 1991;59:493-6.

43 Musa MO, Nounou R, Sahovic E, Seth P, Qadi A, Aljurf M. Fulminant thrombotic thrombocytopenic purpura in two patients with systemic lupus erythematosus and phospholipid autoantibodies. Eur J Haematol 2000;64:433-5

44 Musio F, Bohen EM, Yuan CM, Welch PG. Review of thrombotic thrombocytopenic purpura in the setting of systemic lupus erythematosus. Semin Arthritis Rheum 1998;28:1-19.

45 Neuwelt CM, Daikh DI, Linfoot JA, Pfister DA, Young RG, Webb RL, et al. Catastrophic antiphospholipid syndrome: response to repeated plasmapheresis over three years. Arthritis Rheum 1997;40:1534-9.

46 Nochy D, Daugas E, Droz D, Beaufils H, Grünfeld JP, Piette JC, et al. The intrarenal vascular lesions associated with antiphospholipid syndrome. J Am Soc Nephrol 1999; 10:507-18.

47 Ornstein MH, Rand JH. An association between refractory HELLP syndrome and antiphospholipid antibodies during pregnancy; a report of 2 cases. J Rheumatol 1994;21:1360-4.

48 Petras T, Rudolph B, Filler G, Zimmering M, Ditscherlein G, Loening SA, et al An adolescent with acute renal failure, thrombocytopenia and femoral vein thrombosis. Nephrol Dial Transplant 1998;13:480-3 
49 Sakaguchi S, Kitazawa K, Watanabe M, Mukai K, Totsuka D, Shibata T, et al. A case of primary antiphospholipid antibody syndrome with acute renal failure showing thrombotic microangiopathy. Am J Nephrol 1999;19:594-8.

50 Vivaldi P, Andreotti C, Mazzon C, Pedrazzoli M. A "primitive" catastrophic antiphospholipid syndrome. Haematologica 1994;79:173-6.

51 Zakynthinos EG, Vassilakopoulos T, Kontogianni DD, Roussos C, Zakynthinos SG. A role for transoesophageal echocardiography in the early diagnosis of catastrophic antiphospholipid syndrome. J Intern Med 2000;248:519-24.

52 Cervera R, Khamashta MA, Font J, Sebastiani GD, Gil A, Lavilla P, et al. Systemic lupus erythematosus: clinical and immunologic patterns of disease expression in a cohort of 1,000 patients. The European Working Party on Systemic Lupus Erythematosus. Medicine (Baltimore) 1993;72:113-24.

53 Nesher G, Hanna VE, Moore TL, Hersh M, Osborn TG. Thrombotic microangiographic hemolytic anemia in systemic lupus erythematosus. Semin Arthritis Rheum 1994;24:165-72.

54 Caporali R, Choucair J, Bobbio-Pallavicini E, Porta C, Montecucco C. Autoantibody profile in thrombotic thrombocytopenic purpura. Transfus Sci 1992;13:33-6.

55 Montecucco C, Di Lauro M, Bobbio-Pallavicini E, Longhi M, Caporali R, De Gennaro F, et al. Anti-phospholipid antibodies and thrombotic thrombocytopenic purpura. Clin Exp Rheumatol 1987;5:355-8.

56 von Tempelhoff GF, Heilmann L, Spanuth E, Kunzmann E, Hommel G. Incidence of the factor $V$ Leiden-mutation, coagulation inhibitor deficiency, and elevated antiphospholipid-antibodies in patients with preeclampsia or HELLP-syndrome. Hemolysis, elevated liver-enzymes, low platelets. Thromb Res 2000;100:363-5.

57 Dang CT, Magid MS, Weksler B, Chadburn A, Laurence J. Enhanced endothelial cell apoptosis in splenic tissues of patients with thrombotic thrombocytopenic purpura. Blood 1999:93:1264-70.

58 Mitra D, Jaffe EA, Weksler B, Haijar KA, Soderland C, Laurence J. Thrombotic thrombocytopenic purpura and sporadic hemolytic-uremic syndrome plasmas induce apoptosis in restricted lineages of human microvascular endothelial cells. Blood 1997;89:1224-34.

59 Furlan M, Robles R, Galbusera M, Remuzzi G, Kyrle PA, Brenner B, et al. von Willebrand factor-cleaving protease in thrombotic thrombocytopenic purpura and the hemolytic-uremic syndrome. N Engl J Med 1998;339:1578-84.

60 Tsai HM, Lian EC. Antibodies to von Willebrand factor-cleaving protease in acute thrombotic thrombocytopenic purpura. N Engl J Med 1998;339:1585-94.

61 Yamazaki S, Taki M, Yasumuro Y, Takayama S, Miyake F, Fujimura Y, et al. Von Willebrand factor-cleaving protease activity in patients of collagen disease with antiphospholipid antibodies. Rinsho Byori 2002;50:301-7.

62 Diez-Ewald M, Torres-Guerra E, Vizcaino G, Arteaga-Vizcaino M. Platelet function in patients with lupus anticoagulant and thrombosis. Invest Clin 1995; 36:13-21.

63 Schinco P, Borchiellini A, Tamponi G, Montaruli B, Garis G, Bazzan M, et al Lupus anticoagulant and thrombosis: role of von Willebrand factor multimeric forms. Clin Exp Rheumatol 1997;15:5-10.
64 Mukai M, leko M, Atsumi T, Notoya A, Kohno M. Multiple thromboses in major arteries in a patient with antiphospholipid syndrome associated with excess of a large multimer of von Willebrand factor. Lupus 2001;10:895-6.

65 Matsuda J, Sanaka T, Gohchi K, Matsui K, Uchida S, Matsumoto M, et al. Occurrence of thrombotic thrombocytopenic purpura in a systemic lupus erythematosus patient with antiphospholipid antibodies in association with a decreased activity of von Willebrand factor-cleaving protease. Lupus 2002; 11:463-4

66 Elliott M, Nichols W. Thrombotic thrombocytopenic purpura and hemolytic uremi syndrome. Mayo Clinic Proc 2001 76:1154-62.

67 Heyl W, Handt S, Reister F, Gehlen J, Schroder W, Mittermayer C, et al. Elevated soluble adhesion molecules in women with pre-eclampsia. Do cytokines like tumour necrosis factor-alpha and interleukin-1 beta cause endothelial activation. Eur J Obstet Gynecol Reprod Biol 1999:86:35-41.

68 Lip GYH, Edmunds E, Hee FLLS, Blann AD, Beevers DG. A cross-sectional, diurnal, and follow-up study of platelet activation and endothelial disfunction in malignant phase hypertension. Am J Hypertens 2001;14:823-8.

69 Nakamura N, Shidara Y, Kawaguchi N, Azuma C, Mitsuda N, Onishi S, et al. Lupus anticoagulant autoantibody induces apoptosis in umbilical vein endothelial cells: involvement of annexin V. Biochem Biophys Res Commun 1994;205: 1488-93

70 Simantov R, LaSala JM, Lo SK, Gharavi AE, Sammaritano LR, Salmon JE, ef al. Activation of cultured vascular endothelial cells by antiphospholipid antibodies. J Clin Invest 1995:96:2211-19.

71 Moake JL. Mechanisms of disease - thrombotic microangiopathies. N Engl J Med 2002;347:589-600.

72 Mori Y, Wada H, Gabazza EC, Minami N, Nobori T, Shiku H, et al. Predicting response to plasma exchange in patients with thrombotic thrombocytopenic purpura with measurement of vWF-cleaving protease activity. Transfusion 2002;42:572-80.

73 Veyradier A, Obert B, Houllier A, Meyer D, Girma JP. Specific von Willebrand factor-cleaving protease in thrombotic microangiopathies: a study of 111 cases. Blood 2001;98:1765-72.

74 Hashimoto K, Tabata N, Fujisawa R, Matsumura H, Miyazawa M. Induction of microthrombotic thrombocytopenia in normal mice by transferring a platelet-reactive, monoclonal anti-gp70 autoantibody established from MRL/ pr mice: an autoimmune model of thrombotic thrombocytopenic purpura. Clin Exp Immunol 2000:119:47-56.

75 George JN. How I treat patients with thrombotic thrombocytopenic purpurahemolytic uremic syndrome. Blood 2000;96:1223-9.

76 McLeod BC, Sniecinski I, Ciavarella D, Owen H, Price TH, Randels MJ, et al. Frequency of immediate adverse effects associated with therapeutic apheresis. Transfusion 1999:39:282-8.

77 Goodnough LT, Brecher ME, Kanter MH, AuBuchon JP. Medical progress transfusion medicine (first of two parts) - blood transfusion. N Engl J Med 1999;340:438-47.

78 Brandt JT, Triplett DA, Alving B, Scharrer I. Criteria for the diagnosis of lupus anticoagulant: an update. Subcommittee on Lupus Anticoagulant/ Antiphospholipid Antibody of the Scientific and Standardisation Committee of the ISTH. Thromb Haemost 1995;74:1185-90. 